\title{
Hematological Characteristics in Neonates With Twin-Twin Blood Transfusion
}

\author{
Sayuri Kondo ${ }^{\text {, }}$ Yosuke Sugita ${ }^{\text {a }}$, Shunji Suzuki ${ }^{\mathrm{a}}$,
}

\begin{abstract}
We encountered a case of subacute twin-twin transfusion syndrome (TTTS) with the increased inter-twin reticulocyte count-ratio (calculated by dividing the reticulocyte count of the donor by the reticulocyte count of the recipient). In the current case, inter-twin reticulocyte count-ratio was increased to 1.91 (normal $<1.7$ ); however, we diagnosed the case as subacute TTTS because a myocardial hypertrophy indicating the presence of chronic heart load was not recognized in the twins.
\end{abstract}

Keywords: Twin-twin transfusion syndrome; Twin anemia-polycythemia sequence; Reticulocyte

\section{Introduction}

Twin anemia-polycythemia sequence (TAPS) is a rare form of twin-twin transfusion syndrome (TTTS), which is characterized by the presence of large inter-twin hemoglobin difference without signs of twin oligo-polyhydramnios sequence [1, 2]. Postnatal diagnosis of TAPS is based on the presence of chronic anemia with reticulocytosis (as a sign of chronic anemia) in the donor twin and polycythemia in the recipient $[1,2]$. Usually, TAPS has been diagnosed based on the postnatal criteria defined as inter-twin hemoglobin difference $>8 \mathrm{~g} / \mathrm{dL}$ and inter-twin reticulocyte count-ratio (calculated by dividing the reticulocyte count of the donor by the reticulocyte count of the recipient) $>1.7[3,4]$. The criterion concerning the increased inter-twin reticulocyte count-ratio is based on a previous casecontrol study (sensitivity and specificity of $100 \%$ ) by Lopriore et al [5]. However, we encountered a case of subacute TTTS with the increased inter-twin reticulocyte count-ratio.

Manuscript submitted July 24, 2017, accepted August 11, 2017

aDepartment of Obstetrics and Gynecology, Japanese Red Cross Katsushika Maternity Hospital, Tokyo, Japan

${ }^{b}$ Corresponding Author: Shunji Suzuki, Department of Obstetrics and Gynecology, Japanese Red Cross Katsushika Maternity Hospital, 5-11-12 Tateishi, Katsushika-ku, Tokyo 124-0012, Japan. Email: czg83542@mopera.ne.jp

doi: https://doi.org/10.14740/jmc2882w

\section{Case Report}

A 32-year-old woman, gravida 1, para 0 was referred to our hospital at 29 weeks of gestation for a high-risk obstetric consultation due to monochorionic-diamniotic twin pregnancy with premature labor and selective intrauterine fetal growth restriction. At this time, the estimated fetal weights of twin A and B were 1,277 g (-0.45 SD) and 1,039 g (-0.181 SD), respectively. The amniotic fluid pockets of twin A and B were 6.2 and $4.1 \mathrm{~cm}$, respectively. The Doppler evaluations of umbilical and cerebral arteries of both twins were normal.

At 33 weeks and 6 days of gestation, the fetal cardiotocograms showed reassuring status of both twins. At this time, the Doppler evaluations of both twins were normal. The amniotic fluid pockets of twin A and B were 4.2 and $2.4 \mathrm{~cm}$, respectively. The middle cerebral artery peak systolic velocity (MCA-PSV) in twin A was $39.6 \mathrm{~cm} / \mathrm{s}$ (normal: $<70 \mathrm{~cm} / \mathrm{s}$ ). At 34 weeks and 1 day of gestation, however, the fetal cardiotocograms showed sinusoidal pattern in twin A. The MCA-PSV of twin A was increased to $90.4 \mathrm{~cm} / \mathrm{s}$. An emergency cesarean section was performed. Twin A was a male baby weighing 1,932 $\mathrm{g}$ (appropriate for gestational age) with Apgar score of 8 (1 min) and 9 (5 min), respectively, while twin $\mathrm{B}$ was a male baby weighing 1,680 g (light for gestational age; $13.0 \%$ growth discordance between the twins) with Apgar score of 8 (1 $\mathrm{min})$ and $9(5 \mathrm{~min})$, respectively. The umbilical artery $\mathrm{pH}$ values in twin A and $\mathrm{B}$ were 7.315 and 7.295, respectively. The hemoglobin concentration of twin A was $26.8 \mathrm{~g} / \mathrm{dL}$ (normal: 13 - $22 \mathrm{~g} / \mathrm{dL}$ ) with reticulocyte counts of $3.2 \%$ (normal: $<7 \%$ ), while it was $3.4 \mathrm{~g} / \mathrm{dL}$ with reticulocyte counts of $6.5 \%$ in twin $\mathrm{B}$. The placenta was confirmed as monochorionic with two superficial arterio-venous anastomoses without color difference in placentas.

\section{Discussion}

In the current case, anemia was recognized in the larger twin with more amniotic fluid, and polycythemia was recognized in the smaller twin with less amniotic fluid. In addition, a myocardial hypertrophy indicating the presence of chronic heart load was not recognized in the twins with polycythemia. The findings are contrary to those of slow process of transfusion; therefore, we diagnosed the case as subacute TTTS despite the increased inter-twin reticulocyte count-ratio of $1.91(>1.7)$. 
The placenta without color difference will also support our postnatal diagnosis, because color difference in placenta has been reported to be an additional diagnostic criterion of TAPS $[6,7]$. Whether or not the reticulocyte level exceeds the normal range may be corresponded to the pathognomonic for TAPS with slowly developed anemia more than inter-twin reticulocyte count-ratio. The hematological characteristics of TAPS can be clarified by the accumulation of similar case reports.

\section{References}

1. Lopriore E, Middeldorp JM, Oepkes D, Kanhai HH, Walther FJ, Vandenbussche FP. Twin anemia-polycythemia sequence in two monochorionic twin pairs without oligo-polyhydramnios sequence. Placenta. 2007;28(1):47-51.

2. Lopriore E, Oepkes D. Fetal and neonatal haematological complications in monochorionic twins. Semin Fetal Neonatal Med. 2008;13(4):231-238.
3. Ashwal E, Yinon Y, Fishel-Bartal M, Tsur A, Chayen B, Weisz B, Lipitz S. Twin anemia-polycythemia sequence: perinatal management and outcome. Fetal Diagn Ther. 2016;40(1):28-34.

4. Slaghekke F, Kist WJ, Oepkes D, Pasman SA, Middeldorp JM, Klumper FJ, Walther FJ, et al. Twin anemiapolycythemia sequence: diagnostic criteria, classification, perinatal management and outcome. Fetal Diagn Ther. 2010;27(4):181-190.

5. Lopriore E, Slaghekke F, Oepkes D, Middeldorp JM, Vandenbussche FP, Walther FJ. Hematological characteristics in neonates with twin anemia-polycythemia sequence (TAPS). Prenat Diagn. 2010;30(3):251-255.

6. Tollenaar LS, Zhao DP, Middeldorp JM, Slaghekke F, Oepkes D, Lopriore E. Color difference in placentas with twin anemia-polycythemia sequence: an additional diagnostic criterion? Fetal Diagn Ther. 2016;40(2):123-127.

7. Suzuki S. Twin anemia-polycythemia sequence with placental arterio-arterial anastomoses. Placenta. 2010;31(7):652. 